\title{
Гамова Н.А.
}

доцент кафедры прикладной математики, Оренбургский государственный университет, Оренбург

Равилов В.P., Лехнер В.E.

Студенты группы 20А(ба)СВС, Оренбургский

государственный университет, Оренбург

\section{МАТЕМАТИКА, КАК НЕОТЬЕМЛЕМАЯ ЧАСТЬ АВИАЦИИ}

Аннотация. Роль математики и математического моделирования актуализируется практически во всех профессиональных сферах жизнедеятельности современного человека. Важное значение здесь имеют знания исторических предпосылок создания и развития математики; ее вклада в научно-технический прогресс человеческого общества. Одной из таких сфер, в которой математика имеет колоссальное значение, является авиационная и ракетно-космическая техника. Основной целью данной статьи является изучение роли математики в качестве неотъемлемой части авиации. Понимание взаимосвязи в развитии современной математики и авиации позволяет студентам, будущим специалистам в области авиастроения, глубже осознать специфику учебного курса математики. Знание истории создания и развития математики и авиации помогает студентам выявить гносеологический процесс в прикладной математике. В результате у них создается правильное представление о путях приобретения человечеством знаний об окружающем нас мире, о развитии методов этого познания.

Ключевые слова. Математика, моделирование, авиация. 


\title{
MATHEMATICS AS AN INTEGRAL PART OF AVIATION
}

\author{
Ravilov V.R., Lehner V.E.
}

Annotation. The role of mathematics and mathematical modeling is actualized in almost all professional spheres of life of a modern person. Knowledge of the historical preconditions for the creation and development of mathematics is of great importance here; its contribution to the scientific and technological progress of human society. One of such areas in which mathematics is of colossal importance is aviation and rocket and space technology. The main purpose of this article is to explore the role of mathematics as an integral part of aviation. Understanding the relationship in the development of modern mathematics and aviation allows students to better understand the specifics of the mathematics curriculum. Knowledge of the history of the creation and development of mathematics and aviation helps students to identify the epistemological process in applied mathematics. As a result of this, a correct idea is created about the ways of acquiring knowledge of the world around us by humanity, about the development of the methods of this knowledge.

Key words. Mathematics, modeling, aviation.

Математика является одной из самых древнейших и фундаментальных наук, методы которой повсеместно используются практически во всех дисциплинах и сферах деятельности человеческой жизни. Одни из первых математических понятий и представлений человек формировал в глубокой древности, решая простые задачи прикладного характера. В результате деятельности происходило усложнение форм трудовой деятельности, что открывало перед человеком новые и сложные задачи. Таким образом, создавались новые математические понятия и формировалась математическая теория. Одним из наиболее зависимых относительно математического аппарата направлений в современном мире является авиация. Возникновение авиации неразрывно связано с применением математики для анализа 
основных проблем полета, конструирования и расчета самолётов. Пользуясь аппаратом чистой математики, Н.Е. Жуковский вывел математическую формулу для подъемной силы, действующей на единицу длины крыла [1]:

$$
\mathrm{F}=\rho \mathrm{v} \Gamma,
$$

где $\rho$ - плотность воздуха, v - скорость движения крыла, а Г - циркуляция.

Авиастроение является ключевой ветвью современного научнотехнического прогресса. Между существующими на сегодняшний день самолетостроительными фирмами происходит активное состязание, связанное с созданием техники, превосходящей аналоги конкурентов. Для исследований в современной авиационной науке свойственно использование адекватных математических моделей, основа которых - чёткое понимание физики исследуемых явлений. Разработка и конструирование новых самолётов невозможны без применения «высоко-математизированных» наук, смотри рисунок 1, Направления использования математики в авиации [2].

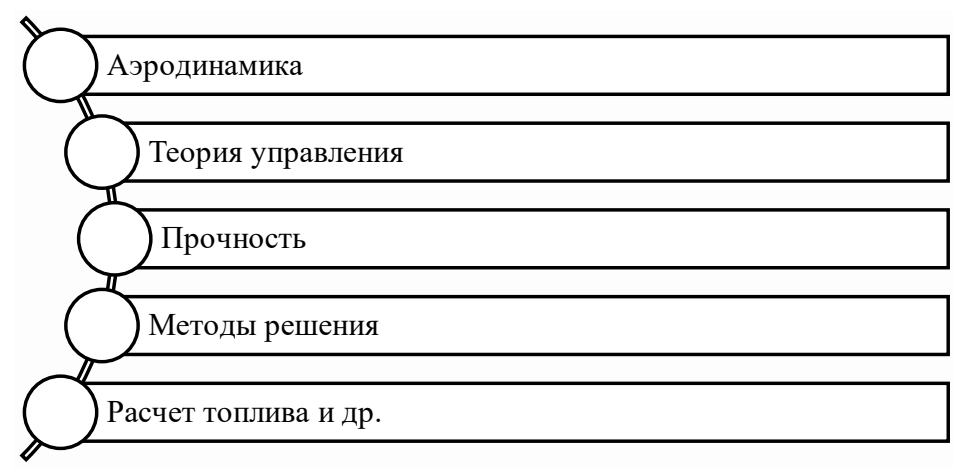

Рис. 1. Направления использования математики в авиации

Аэродинамика. Данное направление включает в себя взаимосвязь воздушного потока и обтекаемости тела. Основная проблема турбулентности математического характера заключается в создании системы дифференциальных уравнений в частных производных, посредством которой происходило бы описание произвольных турбулентных течений. Поэтому в настоящее время на основе уравнений математической физики создаются 
полуэмпирические модели турбулентности, пригодные для описания лишь узкого класса течений [3].

Теория управления. Данное направление связано с изучением полета авиационной техники, который включает в себя такие основные фазы, как: взлет, набор высоты, крейсерское движение, разворот, снижение и посадку. На каждом из данных этапов самолетом необходимо управлять. Данное управление базируется на основе теории дифференциальных уравнений. Также посредством этой же теории производится создание математических моделей пространственного движения самолёта, исследуются вопросы устойчивости полёта [4].

Прочность. Мало создать самолёт с хорошими аэродинамическими данными, необходимо, чтобы он не разрушился в полёте, чтобы его ресурс (долголетие) был достаточно высок. Математический арсенал для решения задач прочности включает классические и современные методы уравнений математической физики, дифференциальных уравнений, вариационного исчисления, комплексного анализа, вычислительных разделов линейной алгебры.

XXI век поставил перед нами довольно жесткие требования к летательным аппаратам, в первую очередь экологические. И в зависимости от того, какой самолет удовлетворяет этим требованиям, его относят к прогрессивным или не прогрессивным. Эти требования влияют и на экономическую стимуляцию. Это отражается на покупательной способности новых марок самолетов. Поэтому все стремятся удовлетворять эти требования, попасть в группу перспективной техники. Проведенный анализ позволил нам сформировать то пространство, в котором мы видим развитие будущего авиационной техники - это создание энергетических установок нового типа, соответствующих требованиям XXI века.

Самолёты совершенствуются, во многом - благодаря математическим достижениям, которые воплощаются в технические решения. В современной авиации расчитывается множество параметров, связанных с математическими 
расчетами. Это и размеры самолетов, высота, расстояние, скорость полета, количество грузов и пассажиров, заправка топливом. В общем, без использования математических знаний не обходится ни один из полетов самолетов [5].

Таким образом, основной целью представленной статьи является изучение актуальности и роли математического аппарата в сегменте авиационной и ракетно-космической техники. В результате исследования были изучены такие аспекты, как: взаимосвязь математики и авиационной техники; направления использования математики в авиации; актуальность исследования математического аппарата при создании авиационной техники. Мы рассмотрели связки между фундаментальной наукой, прикладной наукой математикой и теми задачами, которые сейчас у нас в авиации стоят. Именно посредством использования математического аппарата появляется возможность наиболее эффективного и оптимального проектирования и разработки воздушных средств.

\section{Список литературы}

1. Безъязычный В.Ф. Математические методы в технологии машиностроения // Ярославский педагогический вестник. 2010.

2. Мартынов В.Г. Применение математического моделирования для оптимизации производственных процессов // ОмГТУ. 2014.

3. Volyntsev A.A., Kazakov B.A., Shustov I.E. Gyroscopic angular velocity vector meter. Experience in the study of failures in operation // Bulletin of the Bauman Moscow State Technical University. The series «Instrumentation». 2015.

4. Барабаш А.Д., Мерзликин И.Н. Идентификация отказов систем управления воздушных судов с помощью функций чувствительности // Научный вестник МГТУ ГА. 2015. 
5. Jabborov N.I., Sergeev A.V., Mathematical models of probabilistic characteristics of traction resistance of tillage working bodies // Agroecoengineering. 2019. 